\title{
Prevalence and correlates of HIV infection and HIV testing among transgender women in Jamaica
}

\author{
Logie, Carmen H.; Lacombe-Duncan, Ashley; Wang, Ying; Jones, \\ Nicolette; Levermore, Kandasi; Neil, Ava; Ellis, Tyrone; Bryan, \\ Nicolette; Harker, Sheldon; Marshall, Annecka; \\ and Newman, Peter A.
}

Version Post-Print/ Accepted Manuscript

Citation Logie Carmen H., Lacombe-Duncan Ashley, Wang Ying, Jones

(published version) Nicolette, Levermore Kandasi, Neil Ava, Ellis Tyrone, Bryan Nicolette, Harker Sheldon, Marshall Annecka, and Newman Peter A. (2016). Prevalence and correlates of HIV infection and HIV testing among transgender women in Jamaica. AIDS Patient Care and STDs 30(9): 416424. doi:10.1089/apc.2016.0145.

Publisher's Statement Final publication is available from Mary Ann Liebert, Inc., publishers http://dx.doi.org/10.1089/apc.2016.0145.

How to cite TSpace items

Always cite the published version, so the author(s) will receive recognition through services that track citation counts, e.g. Scopus. If you need to cite the page number of the TSpace version (original manuscript or accepted manuscript) because you cannot access the published version, then cite the TSpace version in addition to the published version using the permanent URI (handle) found on the record page. 


\section{Prevalence and correlates of HIV infection and HIV testing among transgender women in Jamaica}

Carmen H. Logie, Ph.D. ${ }^{1,2}$, Ashley Lacombe-Duncan, M.S.W. ${ }^{1}$, Ying Wang, M.S.W. ${ }^{1}$, Nicolette Jones, M.A. ${ }^{3}$, Kandasi Levermore, B.Sc. ${ }^{3}$, Ava O'Neill ${ }^{3}$, Tyrone Ellis ${ }^{3}$, Nicolette Bryan, B.A. ${ }^{3,4}$, Sheldon Harker, B.A. ${ }^{3}$, Annecka Marshall, Ph.D. ${ }^{4}$, Peter A. Newman, Ph.D. ${ }^{1}$

${ }^{1}$ Factor-Inwentash Faculty of Social Work, University of Toronto, Toronto, Canada

${ }^{2}$ Women's College Research Institute, Women's College Hospital, Toronto, Canada

${ }^{3}$ Jamaica AIDS Support for Life, Kingston, Jamaica

${ }^{4}$ Women's Empowerment for Change (WE-Change), Kingston, Jamaica

Campus, Kingston, Jamaica

${ }^{5}$ Institute for Gender and Development Studies, University of the West Indies, Mona

Corresponding Author:

Carmen H. Logie

Faculty of Social Work, University of Toronto

246 Bloor Street West

Toronto, ON, M5S 1V4, Canada

Tel: 1 (647) 4544203

Fax: 1 (416) 9787072

carmen.logie@utoronto.ca 


\begin{abstract}
Transgender women are overrepresented in the Caribbean's HIV epidemic. The study objective was to examine correlates of HIV infection and HIV testing among transgender women in Jamaica. We implemented a cross-sectional survey with transgender women in Kingston and Ocho Rios, Jamaica. We conducted multivariable logistic regression to identify factors associated with HIV testing and HIV infection. Among 137 transgender women (mean age: 24.0 [SD: 5.5]), three-quarters $(n=103,75.7 \%)$ had received an HIV test. Of these, one-quarter $(n=26$, 25.2\%) were HIV-positive. In multivariable analyses, HIV testing was associated with: perceived HIV risk (AOR: 2.42, CI: 1.36-4.28), depression (AOR: 1.34, CI: 1.01-1.77), forced sex (AOR: 3.83, CI: 1.42-10.35), physical abuse (AOR: 4.11, CI: 1.44-11.72), perceived transgender stigma (AOR: 1.23, 1.06-1.42), having a healthcare provider (AOR: 5.89, CI: 1.46-23.77), and lower HIV-related stigma (AOR: 0.96, CI: 0.92-0.99), incarceration (AOR: 0.28, CI: 0.10-0.78), and drug use (AOR: 0.74, CI: 0.58-0.95). HIV infection was associated with: homelessness (AOR: 5.94, CI: 1.27-27.74), perceived HIV risk (AOR: 1.67, CI: 1.02-2.72), depression (AOR: 1.39, CI: 1.06-1.82), STI history (AOR: 56.79, CI: 5.12-630.33), perceived (AOR: 1.26, CI: 1.06-1.51) and enacted (AOR: 1.16, CI: 1.04-1.29) transgender stigma, forced sex (AOR: 4.14, CI: 1.4911.51), physical abuse (AOR: 3.75, CI: 1.39-10.12), and lower self-rated health [AOR: 0.55, CI: 0.30-0.98) and social support (AOR: 0.79, CI: 0.64-0.97). Transgender women in Jamaica experience high HIV infection rates and suboptimal HIV testing. Combination HIV prevention approaches should address transgender women's social and structural vulnerabilities.
\end{abstract}

Keywords: transgender, Jamaica, HIV, stigma, discrimination, testing 


\section{INTRODUCTION}

HIV disproportionately affects transgender women in the global pandemic, including in Caribbean countries. ${ }^{1,2}$ Latin American-based studies, some of which include the Caribbean, report that over one-quarter of transgender women are living with HIV. ${ }^{3}$ A systematic review and meta-analysis including transgender women $(\mathrm{n}=7179)$ purposively sampled from ten lowand middle-income countries (LMIC) reported an HIV prevalence of 17.7\% (95\% CI: 15.619.8). ${ }^{4}$ Transgender women experience HIV rates almost 49 times higher than national prevalence estimates across high and LMIC. ${ }^{4}$ Yet in Caribbean contexts, ${ }^{5}$ including in Jamaica, there is limited knowledge about HIV prevention and care needs among transgender women.

Jamaica is one of several Caribbean countries that has established a comprehensive response to the HIV epidemic, ${ }^{6}$ resulting in a substantially reduced HIV incidence and a current HIV prevalence of $1.7 \%$ (95\% CI: $1.4-2.0)$ among the adult general population. ${ }^{7}$ Yet the criminalization of "homosexuality" in Jamaica may contribute to elevated HIV infection rates among sexual and gender minorities (SGM). For example, the estimated HIV prevalence among men who have sex with men (MSM) in Jamaica is between $28 \%$ to $32 \%$, among the highest in the Caribbean. ${ }^{8,9}$ Scant research has examined HIV prevalence among transgender women in Jamaica, who face similar experiences of stigma and discrimination as MSM. Figuero et al.'s 9 study with MSM (n=449) in Jamaica included 17 transgender women with reported HIV infection rates of $52.9 \%$. We located no studies focused on assessing HIV prevalence, correlates of HIV testing, or correlates of HIV infection among transgender women in Jamaica.

Social and structural drivers that elevate transgender women's HIV exposure include the criminalization of homosexuality, violence, stigma and discrimination. Criminalization of SGM limits access to the HIV prevention and care continuum, ${ }^{10}$ from HIV testing and diagnosis to viral suppression. ${ }^{10-12}$ Community-based organizations report pervasive violence towards SGM 
populations from both within their families and in the broader community. ${ }^{13,14}$ Globally transgender women experience higher rates of violence and incarceration than non-transgender women. ${ }^{15}$

SGM in Caribbean countries experience stigma and discrimination, family rejection, and a lack of human rights protections in employment, education systems, and the State. ${ }^{16}$ These factors contribute to economic insecurity, including poverty and homelessness, that elevate HIV vulnerability ${ }^{16,17}$ and decrease access to HIV testing. ${ }^{18}$ Economic insecurity plays a role in the high rates of sex work among transgender populations, particularly in Caribbean and Latin American countries, with upwards of $60 \%$ of samples reporting sex work involvement. ${ }^{19,15}$ HIVrelated stigma also presents a formidable barrier to HIV testing uptake in Jamaica. In a study of incarcerated men in Jamaica (n=298), HIV-related stigma was associated with decreased likelihood of ever receiving an HIV test. ${ }^{20}$ In a qualitative study with health and social service providers, PLHIV and SGM reported that both HIV-related and sexual stigma reduced uptake of, and access to, HIV testing, treatment and care services. ${ }^{21}$ The lack of confidentiality about sexuality and HIV in health care facilities leads to distrust that reduces health services utilization. $^{22}$

Understanding factors associated with HIV infection and HIV testing among transgender women in the Jamaican is critical to enhance access to the HIV care cascade. HIV testing is the first step in the HIV care cascade, facilitating diagnosis and linkage to care, initiation of antiretroviral treatment, and viral suppression - which may optimize the health of transgender women as well as prevent HIV transmission. ${ }^{11}$

\section{Study objectives}


The study objective was to enhance knowledge of correlates of HIV infection and HIV testing uptake among transgender women in Jamaica. We aimed to: 1) determine HIV prevalence and the proportion of participants ever tested for HIV; and, 2) determine correlates of HIV infection and ever having received an HIV test.

\section{METHODS}

\section{Sampling and data collection}

In collaboration with a national AIDS Service Organization (X: blinded for peer review) we conducted a cross-sectional survey with transgender women in Kingston and Ocho Rios, Jamaica, as well as from surrounding areas of these cities between March 2015-October 2015. Participants were eligible to complete the survey if they identified as a transgender women over 18 years old currently residing in Jamaica.

We utilized purposive, non-random sampling methods to access this highly marginalized population. There were no print materials (e.g. flyers, posters) due to the lack of legal protection among transgender women in Jamaica. We recruited and trained 7 peer research assistants (PRAs) across study sites who self-identified as a sexual or gender minorities (lesbian, gay, bisexual, transgender). We used snowball sampling methods with PRAs and participants to recruit transgender women participants ${ }^{23}$; snowball sampling methods facilitating reaching hidden populations, ${ }^{24,25}$ such as transgender people. ${ }^{26}$ PRAs in each venue were involved in conducting HIV outreach at the (X ASO), including a mobile testing service that provided HIV testing and access to HIV prevention materials (e.g. condoms, lubricant). The PRAs who were conducting HIV outreach shared study information with potential participants and also shared the study information with their social networks. Each participant of the study was also provided the opportunity to invite additional participants through sharing up to 5 study coupons with persons 
in their social networks, and participants received $\$ 500$ Jamaican dollars (approximately $\$ 4$ USD) for each participant they recruited up to a maximum of five participants. PRA recorded the identification number for each coupon used for recruitment purposes. This process allowed for voluntary HIV testing of participants and matching HIV testing uptake and HIV test results to each participant survey ID.

The survey was interviewer administered on tablets in a location of the participant's choice (e.g. home, park, X ASO). The survey took 30 minutes to complete and participants received a $\$ 1000$ Jamaican dollars (approximately \$8 USD) honorarium for their time. Participants were offered a \$500 Jamaica dollars (approximately \$4 USD) phone card for completing voluntary HIV testing and post-test counselling at (X ASO) upon presentation of the coupon with their unique participant identification (ID) number. Tests were offered to all study participants, regardless of HIV status or self-reported past HIV testing. Tests were done by a trained nurse at (X ASO) using an immunochromatographic HIV rapid test kit (Alere's Determine HIV-1/2). If the rapid HIV test result was positive, a blood sample was taken and sent to the National Laboratory to perform ELISA testing to confirm results. Research ethics approval was granted from Institution A and B (blinded for peer review).

\section{Measures}

Ever HIV tested and HIV status. HIV test ever was measured during survey data collection with the dichotomous question "I have had an HIV test in my lifetime". We also included participants who presented their study coupon to receive a rapid HIV test at X ASO as having ever received an HIV test. If participants responded that they had received an HIV test, they were asked to self-report their HIV status. HIV status was measured by combining selfreported HIV status collected on the survey, and HIV test results from participants who chose to complete HIV testing as part of this study. HIV serostatus was dichotomized to HIV-positive and 
HIV- negative. We assessed differences in socio-demographic and all study variables among persons reporting an HIV-positive status by self-report or in this study's laboratory test.

Socio-demographic factors. Socio-demographic variables included age and monthly income in Jamaican dollars, measured continuously, and city of residence (Kingston, Ochos Rios, with the option to list other places of residence), education level (less than high school, completed high school, attended some college, and completed college or higher), employment status (employed or self-employed full time, employed or self-employed part time, student, receiving assistance, no source of income), relationship status (married or living together, datingnot living together, casual dating, no current partner and multiple partners/polyamorous), and housing status (own house or apartment, family, other people's house or apartment, living outside) measured categorically.

Intrapersonal factors. Perceived HIV risk was assessed using a Likert-scale question "How much do you think you are at risk for HIV infection?" with the options of no risk, low risk, medium risk or high risk. We used the two-item Patient Health Questionnaire-2 (PHQ-2) to screen for depression symptoms over the last 2 weeks $^{27}$ (Cronbach's $\alpha=0.67$ scale range $0-8$ ). A higher score of PHQ-2 reflects increased depression symptoms. Self-rated health was assessed using the World Health Organization's single global self-rated health question (On a scale of 1 [poor] to 4 [excellent], how would you rate your overall health? $)^{28}$ measured on a 4-point Likert scale with a higher response indicating a higher self-rated health. We assessed substance use with the question: "Have you drank alcohol or used drugs in the last 3 months (Yes/No)?" Participants were asked about drug use with the question: "On a scale of 1 (never) to 8 (every day), how often have you used OTHER DRUGS (not alcohol) in the last 3 months?" Lifetime sexually transmitted infections history was measured using two questions: 1) I have had a 
sexually transmitted infections (STI) test (not including HIV) in my lifetime; and if yes, 2) What was the STI test result? Sex work involvement was measured by asking the question: "In the last year have you ever had sex (oral, vaginal, or anal) in exchange for (please check all that apply): 1) a place to stay, food or transportation; 2) money; 3) drugs or alcohol; 4) none of the above." If the answer was affirmative for options 1 through 3 , the response was coded as sex work involvement.

Interpersonal/social factors. We assessed factors related to experiences of forced sex: "In your life have you ever experienced forced sex (for example rape, sexual assault)?" and physical abuse: "In your life have you ever experienced physical abuse? (Abuse is any act to hurt you physically)". We measured social support using a brief social support scale ${ }^{29}$ previously assessed for validity in a Caribbean context (Puerto Rico). The social support measure included two subscales: the need for social support (Cronbach's $\alpha=0.83$, range 5-35) and satisfaction with the quality of social support (Cronbach's $\alpha=0.86$, range $2-10) .{ }^{29}$ We conducted confirmatory factor analysis (CFA) to assess the factor structure of the 2 subscales in the social support measure $(\mathrm{TLI}=0.97, \mathrm{CFI}=0.99, \mathrm{RMSEA}=0.08, p<0.05)$. To assess practices associated with increased risk of HIV acquisition, participants were asked how often they get drunk or high while having sex, measured on a 4-point Likert Scale (1 [never] to 4 [always]), and lifetime number of sexual partners measured continuously.

Structural and healthcare access factors. HIV-related stigma was measured using Steward et al.'s 10-item perceived (also referred to as felt or felt-normative) stigma subscale ${ }^{30}$, with a higher score indicating a higher level of perceived HIV-related stigma (Cronbach's $\alpha=0.89$, range $0-100$ ). Perceived stigma refers to awareness of negative attitudes, beliefs and treatment towards a marginalized group ${ }^{31}$ for example, people living with HIV. This sub-scale 
was validated with HIV-negative MSM and transgender women in LMIC. ${ }^{32,33}$ Items were measured on a 10-point Likert scale from 1 (none) to 10 (most people) (e.g., "In your community how many people think that HIV positive people have brought shame on their families?’)

We utilized an adapted version of Diaz et al.'s ${ }^{34}$ Homophobia Scale to measure enacted (Cronbach's $\alpha=0.77$, range 7-28) and perceived stigma (Cronbach's $\alpha=0.61$, range 5-20) towards transgender persons. The scale was adapted to replace each item "because of your homosexuality" to "because you are transgender". Enacted stigma refers to discriminatory acts, including violence, harassment and mistreatment. ${ }^{31}$ The perceived transgender stigma scale includes items such as "How often have you heard that transgender people are not normal?" and the enacted transgender stigma scale includes items such as "How often have you been hit or beaten up for being transgender?" We assessed the factor structure of the 2 dimensional (perceived, enacted) transgender stigma scale using CFA (TLI=0.91, CFI $=0.93$, RMSEA $=0.11$, $p<0.05)$.

Having a healthcare provider was measured dichotomously with the question "Do you have a regular health care provider?" A history of incarceration for being transgender was measured dichotomously with the question "Have you ever been in jail for being transgender?" Housing security was measured by asking: "In the past month, where have you usually slept? (a) In my own house or apartment; (b) in other people's house or apartment; (c) outside (homeless)".

\section{Data analysis}

We conducted descriptive analyses for socio-demographic variables (e.g. age, income) in order to determine frequencies and proportions for categorical variables, and means and standard deviations for continuous variables. Descriptive analyses included all participants with available data. We conducted bivariate logistic regression followed by multivariate logistic regression controlling for factors correlated at $p<0.05$ (age and monthly income) for each outcome (ever 
HIV tested and HIV status) separately. Multivariate logistic regression allows for the determination of appropriate estimates of the adjusted risk ratio for having ever received an HIV test and HIV serostatus among transgender women in Jamaica. We report the unadjusted and adjusted odds ratios and $95 \%$ confidence intervals, highlighting those significant at the 0.05 level. Missing responses were excluded from the analyses; the number of complete responses are reported for each variable. All statistical analyses were performed using STATA (version 12.0, College Station, Texas, United States).

\section{RESULTS}

\section{Participant characteristics}

Table 1 reports participant socio-demographic characteristics, HIV testing and prevalence outcomes, and intra/interpersonal and structural factors $(n=137)$. The mean age was 24.0 years (SD: 4.5). Two thirds of the sample (67.2\%) lived in the Kingston area. Participants reported an average monthly income of $\$ 225.5$ USD (SD: 337.9). Less than one-third of participants ( $\mathrm{n}=41$, $30.4 \%$ ) reported having enough money to afford a place to live. Less than one-third of participants $(n=42,30.7 \%)$ had a regular health care provider. Three-quarters $(n=103,75.7 \%)$ of participants had ever received an HIV test. One-quarter $(n=26,25.24 \%)$ of those tested reported being HIV-positive: 15 participants were HIV-positive from our study's laboratory test and 11 self-reported being HIV-positive. Bivariate analysis (T-test, chi square or ANOVA) revealed that there were no significant differences in socio-demographic or other variables between participants who self-reported being HIV-positive and those who received an HIV-positive result in this study's laboratory test.

\section{Univariate and multivariate modeling of HIV testing among transgender women}


In univariate analyses (Table 2), perceived poverty, living in Ocho Rios compared to Kingston, perceived HIV risk, depression, forced sex history, physical abuse history, perceived transgender stigma, and having a healthcare provider were associated with increased odds of ever having received an HIV test. Having multiple partners/polyamoury compared to being married, drug use, getting drunk or high when having sex, and HIV-related stigma were associated with decreased odds of ever having received an HIV test.

In multivariate analyses (Table 2), HIV testing was associated with intrapersonal (perceived HIV risk [AOR: 2.42, CI: 1.36-4.28], drug use [AOR: 0.74, CI: 0.58-0.95], depression [AOR: 1.34, CI: 1.01-1.77]), interpersonal/social (getting drunk or high when having sex [AOR: 0.49, CI: 0.25-0.95], forced sex history [AOR: 3.83, CI: 1.42-10.35], physical abuse history [AOR: 4.11, CI: 1.44-11.72]), and structural (perceived transgender stigma [AOR: 1.23, 1.06-1.42], HIV-related stigma [AOR: 0.96, CI: 0.92-0.99], incarceration history for being transgender [AOR: 0.28, CI: 0.10-0.78], having a healthcare provider [AOR: 5.89, CI: 1.4623.77]) factors. The lifetime STI history result is omitted because all of the participants with a lifetime STI history had received an HIV test. With a one-unit increase in HIV-related stigma, the likelihood of HIV testing decreased by $4 \%$. Figure 1 portrays that if a participant scored 25 on the HIV-related stigma scale, the predicted probability of HIV testing was $97.2 \%$, whereas if a participant scored 100 on the HIV-related stigma scale, the predicted probability of HIV testing was $58.4 \%$.

\section{Univariate and multivariate modeling of HIV status among transgender women}

In univariate analyses, perceived poverty, perceived HIV risk, depression, need for social support, forced sex history, physical abuse history, perceived transgender stigma, enacted transgender stigma, lower self-rated health, and homelessness were associated with increased 
odds of being HIV-positive. Being employed and having higher quality of social support were associated with decreased odds of being HIV-positive.

In multivariable analyses (Table 2), being HIV-positive was associated with intrapersonal (perceived HIV risk [AOR: 1.67, CI: 1.02-2.72], depression [AOR: 1.39, CI: 1.061.82], self-rated health [AOR: 0.55, CI: 0.30-0.98], lifetime STI history [AOR: 56.79, CI: 5.12630.33], interpersonal/social (need for social support [AOR: 1.09, CI: 1.01-1.18], quality of social support [AOR: 0.79, CI: 0.64-0.97], having forced sex history [AOR: 4.14, CI: 1.4911.51], physical abuse history [AOR: 3.75, CI: 1.39-10.12]), and structural (perceived transgender stigma [AOR: 1.26, CI: 1.06-1.51], enacted transgender stigma [AOR: 1.16, CI: 1.04-1.29], homelessness [AOR: 5.94, CI: 1.27-27.74]) factors.

Perceived and enacted transgender stigma were higher among HIV-positive participants. With a one unit increase in the perceived transgender stigma score, the likelihood of being HIV positive increased by $26.5 \%$. As shown as Figure 2, the predicted probability of being HIVpositive if a participant scored 5 on the perceived transgender stigma scale was $2.2 \%$, whereas the probability was $27.9 \%$ if the participant scored 20 . With a one unit increase in the score on the enacted transgender stigma scale, the likelihood of being HIV positive increased by $15.7 \%$. Figure 3 depicts that the predicted probability of being HIV positive if a participant scored 7 on the enacted transgender stigma scale was $6.2 \%$, whereas the probability was $54.8 \%$ with a score of 30 .

\section{DISCUSSION}

The high HIV prevalence in this study highlights transgender women in Jamaica as a key population to involve in the HIV prevention and care continuum. Lifetime history of other STIs was highly associated with being HIV-positive, underscoring the need to include STI testing and 
prevention as part of the HIV prevention and care continuum in the Jamaican context. Onequarter of participants were never tested for HIV; with a $25 \%$ rate of seropositivity, this rate of testing is concerning as it is likely that a proportion of our sample are living with HIV undiagnosed, limiting their access to early treatment, care, and support. Importantly, our findings suggest that participants who engaged in practices that elevate the risk of HIV exposure (drug use, getting drunk or high when having sex) were less likely to have received an HIV test. Tailored educational interventions to increase perceived HIV risk among highly marginalized populations (e.g., transgender women who use drugs) may promote HIV testing uptake. Strategies are required to increase accountability, sensitivity and privacy in HIV testing and care services.

Our study highlights complex, multi-level factors associated with HIV testing and HIV infection that reflect the social ecological model. Social ecological perspectives situate HIV risk in larger social and structural contexts, including intrapersonal (e.g., mental health), interpersonal/social (e.g., social support), and structural (e.g., healthcare access, stigma) factors. ${ }^{35}$ HIV-related stigma was a barrier to HIV testing, corroborating qualitative work in Jamaica $^{21}$ and quantitative work in other contexts. ${ }^{33,36-38}$

Transgender stigma was higher among participants who had ever received an HIV test in comparison with those never tested, and higher among HIV-positive participants in comparison with HIV-negative participants. It is plausible that transgender women encounter transgender stigma upon accessing HIV testing and care services. For example, a recent study in Jamaica and the Bahamas with 332 healthcare and social service providers reported stigmatizing attitudes, most strongly in relation to MSM living with HIV. ${ }^{39}$ Prior research in Jamaica has highlighted healthcare worker resistance to working with sexual minorities and PLHIV.${ }^{39-41}$ It is also possible 
that transgender stigma could be a distal HIV risk factor and elevate HIV infection riskslongitudinal studies are warranted to better understand the associations between HIV positive serostatus and transgender stigma. There is a growing body of literature that suggests that HIV self-testing, administered in a location of an individual's choosing, is acceptable to transgender women and may address concerns with privacy, confidentiality, and stigma (HIV-related, transgender) often encountered by transgender women in the context of clinic-based HIV testing. ${ }^{42-44}$ However, in the absence of structural interventions to address stigma in healthcare settings, transgender women living with HIV may continue to experience barriers accessing the HIV care continuum. $^{42}$

HIV positive participants were 6-fold more likely to be homeless, and a history of incarceration was associated with substantially $(>70 \%)$ reduced odds of ever receiving an HIV test. Forced sex and physical violence were associated with both increased odds of being HIV positive and having received an HIV test. Number of sexual partners was only marginally associated ( $\mathrm{p}=0.041$ ) with being HIV positive. It is plausible that HIV infection occurred early in sexual debut; sexual violence may also have increased HIV exposure. Addressing transgender women's survival needs, and reducing violence targeting transgender women, in Jamaica may be key to reducing vulnerability to HIV infection and engaging them in the HIV prevention and care continuum.

There are a few limitations inherent in our study design. The non-random sampling method, while necessary in accessing such a hidden and vulnerable population, limits generalizability of findings to other transgender women in Jamaica. The cross-sectional study design precludes understanding causality and necessitates a cautious interpretation of our findings. Data collected was self-reported, and is therefore subject to recall bias and social 
desirability bias. While we found having multiple partners/polyamoury was associated with HIV testing uptake, future studies could examine multiple partners/polyamoury as a distinct category rather than a relationship status, as persons of various relationship statuses can have multiple partners. We found an overall HIV prevalence of $25 \%$ through combining self-reported HIV status with HIV positive laboratory test results in our study. However, HIV testing was voluntary and only $22 \%$ of participants chose to receive an HIV test in this study. The low rate of testing uptake could be related to high rates of baseline seropositivity; it is also possible that participants who had ever received an HIV test did not feel the need to receive another. Our findings could therefore underreport HIV infection rates among this sample of transgender women.

Despite these limitations, this was among the first studies to assess HIV status and testing rates among transgender women in Jamaica, a highly vulnerable population among whom we identified extremely high HIV prevalence. Combination HIV prevention approaches may be crucial for Jamaican transgender women given the many social-structural vulnerabilities identified; these might include: increased access to voluntary HIV testing and counselling; psychosocial support for depression and substance use; gender-based violence prevention; HIV and transgender stigma reduction campaigns; access to survival needs, in particular employment and housing; and legal protection from discrimination. Future research and interventions could address the syndemics ${ }^{45,46}$ of violence, economic insecurity and mental health challenges that elevate HIV vulnerability among this population. Addressing social ecological contexts of HIV risk is necessary to advance HIV prevention among transgender women in Jamaica. 
Acknowledgements: We would like to thank all of the participants, peer research assistants and collaborators: Jamaica AIDS Support for Life, JFLAG: Jamaica Forum for Lesbians, All-Sexuals and Gays, Caribbean Vulnerable Communities (CVC), Grata Foundation, QCJ: Quality of Citizenship Jamaica, Ashe, Colour Pink Group, Aphrodite's Pride, and the University of the West Indies, Mona Campus. This research was funded by the Canadian Institutes of Health Research Operating Grant 0000303157; Fund: 495419, Competition 201209.

Author Disclosure: The authors have no financial conflicts of interest to declare. 


\section{REFERENCES}

1. Garcia PJ, Bayer A, Carcamo CP. The changing face of HIV in Latin America and the Caribbean. Curr HIV AIDS Reps 2014;11:146-157.

2. Miller WM, Buckingham L, Sanchez-Dominguez MS, et al. Systematic review of HIV prevalence studies among key populations in Latin America and the Caribbean. Salud Publica Mex 2013;55:S65-78.

3. Pan American Health Organization. Blueprint for the provision of comprehensive care for trans persons and their communities in the Caribbean and other anglophone countries. Geneva: World Health Organization; 2014.

4. Baral SD, Poteat T, Strömdahl S, et al. Worldwide burden of HIV in transgender women: a systematic review and meta-analysis. Lancet Infect Dis 2013;13:214-222.

5. Baral S, Holland CE, Shannon K, et al. Enhancing benefits or increasing harms: community responses for HIV among men who have sex with men, transgender women, female sex workers, and people who inject drugs. J Acquir Immune Defic Syndr 2014;66:S319-S328.

6. Figueroa JP, Duncan J, Byfield L, et al. A comprehensive response to the HIV/AIDS epidemic in Jamaica: a review of the past 20 years. West Ind Med J 2008;57:562-576.

7. De Boni R, Veloso VG, Grinsztejn B. Epidemiology of HIV in Latin America and the Caribbean. Curr Opin HIV AIDS 2014;9:192-198.

8. UNAIDS. Jamaica Country Progress Report. Jamaica UNAIDS; 2014.

9. Figueroa JP, Cooper CJ, Edwards JK, et al. Understanding the high prevalence of HIV and other sexually transmitted infections among socio-economically vulnerable men who have sex with men in Jamaica. PLoS One 2015;10:e0117686. 
10. Baral S, Logie C, Grosso A, et al. Modified social ecological model: a tool to guide the assessment of the risks and risk contexts of HIV epidemics. BMC Public Health $2011 ; 13: 482$.

11. Mugavero MJ, Amico KR, Horn T, et al. The state of engagement in HIV care in the United States: from cascade to continuum to control. Clin Infect Dis 2013;57:1164-1171.

12. Cohen J, Lo Y-R, Caceres CF, et al. WHO guidelines for HIV/STI prevention and care among MSM and transgender people: implications for policy and practice. Sex Transm Infect 2013;89:536-538.

13. McFadden D. In Jamaica, Transgender teen murdered by mob. USA Today. 2013.

14. Human Rights Watch. Not safe at home: violence and discrimination against LGBT people in Jamaica. United States: Human Rights Watch;2014.

15. Sevelius JM, Keatley J, Gutierrez-Mock L. HIV/AIDS programming in the United States: considerations affecting transgender women and girls. Women Health Issues 2011;21:S278-282.

16. Allen CF, Simon Y, Edwards J, et al. Factors associated with condom use: economic security and positive prevention among people living with HIV/AIDS in the Caribbean. AIDS Care 2010;22:1386-1394.

17. Figueroa JP, Weir SS, Jones-Cooper C, et al. High HIV prevalence among men who have sex with men in Jamaica is associated with social vulnerability and other sexually transmitted infections. West Ind Med J 2013;62:286-291.

18. Andrinopoulos K, Hembling J, Guardado ME, et al. Evidence of the negative effect of sexual minority stigma on HIV testing among MSM and transgender women in San Salvador, El Salvador. AIDS Behav 2015;19:60-71. 
19. Lee SW, Deiss RG, Segura ER, et al. A cross-sectional study of low HIV testing frequency and high-risk behaviour among men who have sex with men and transgender women in Lima, Peru. BMC Public Health 2015;15:408.

20. Andrinopoulos K, Kerrigan D, Figueroa JP, et al. HIV coping self-efficacy: a key to understanding stigma and HIV test acceptance among incarcerated men in Jamaica. AIDS Care 2010;22:339-347.

21. White RC, Carr R. Homosexuality and HIV/AIDS stigma in Jamaica. Cult Health Sex $2005 ; 7: 347-359$.

22. Kempadoo K, Taitt A. Gender, sexuality and implications for HIV/AIDS in the Caribbean: a review of literature and programmes. Barbados: United Nations Development Fund for Women and International Development Research Centre;2006.

23. Elliott E, Watson AJ, Harries U. Harnessing expertise: involving peer interviewers in qualitative research with hard-to-reach populations. Health Expect 2002;5:172-178.

24. Heckathorn DD. Respondent-driven sampling: a new approach to the study of hidden populations. Soc Probl 1997;44:174-199.

25. Heckathorn DD. Respondent-driven sampling II: deriving valid population estimates from chain-referral samples of hidden populations. Soc Probl 2002;49:11-34.

26. Bauer GR, Travers R, Scanlon K, et al. High heterogeneity of HIV-related sexual risk among transgender people in Ontario, Canada: a province-wide respondent-driven sampling survey. BMC Public Health 2012;12:1-12.

27. Kroenke K, Spitzer RL, Williams JBW. The Patient Health Questionnaire-2: validity of a two-item depression screener Med Care. 2003;41:1284-1292. 
28. World Health Organization. Health interview surveys: towards international harmonization of methods and instruments. In: Netherlands S, ed. Copenhagen (WHO Regional Office for Europe): WHO Regional Publications: European Series; 1996.

29. Bernal G, del Río MS, Maldonado-Molina MM. Development of a brief scale for social support: Reliability and validity in Puerto Rico. Int J Clin Hlth Psyc 2003;3:251-264.

30. Steward WT, Herek GM, Ramakrishna J, et al. HIV-related stigma: adapting a theoretical framework for use in India. Soc Sci Med 2008;67:1225-1235.

31. Herek GM. Confronting sexual stigma and prejudice: theory and practice. J Soc Issues 2007;63:905-925.

32. Logie $\mathrm{CH}$, Newman PA, Chakrapani $\mathrm{V}$, et al. Adapting the minority stress model: associations between gender non-conformity stigma, HIV-related stigma and depression among men who have sex with men in South India. Soc Sci Med 2012;74:1261-1268.

33. Logie $\mathrm{CH}$, Newman PA, Weaver J, et al. HIV-related stigma and HIV prevention uptake among young men who have sex with men and transgender women in Thailand. AIDS Patient Care STDs 2016;30:92.

34. Diaz RM, Ayala G, Bein E, et al. The impact of homophobia, poverty, and racism on the mental health of gay and bisexual Latino men: findings from 3 US cities. Am J Public Health 2001;9:927.

35. Remien RH, Bauman LJ, Mantell JE, et al. Barriers and facilitators to engagement of vulnerable populations in HIV primary care in New York City. J Acqui Immune Defic Syndr 2015;69:S16-S24.

36. Smolak A, El-Bassel N. Multilevel stigma as a barrier to HIV testing in Central Asia: a context quantified AIDS Behav. 2013;17:2742-2755. 
37. Kalichman SC, Simbayi LC. HIV testing attitudes, AIDS stigma, and voluntary HIV counselling and testing in a black township in Cape Town, South Africa. Sex Transm Infect 2003;79:442-447.

38. Fortenberry JD, McFarlane M, Bleakley A, et al. Relationships of stigma and shame to gonorrhea and HIV screening Am J Public Health. 2002;92:378-381.

39. Rogers SJ, Tureski K, Cushnie A, et al. Layered stigma among health-care and social service providers toward key affected populations in Jamaica and The Bahamas. AIDS Care 2014;26:538-546.

40. Bain BC. Improving community care for persons with the acquired immunodeficiency syndrome in Jamaica. West Indian Med J 1998:37-39.

41. Wickramasuriya TV. Attitudes of medical students toward the acquired immune deficiency syndrome (AIDS). West Indian Med J 1995;44:7-10.

42. Bustamante MJ, Konda KA, Joseph Davey D, et al. HIV self-testing in Peru: questionable availability, high acceptability but potential low linkage to care among men who have sex with men and transgender women. Int J STD AIDS. 2016; epub ahead of print.

43. Frye V, Wilton L, Hirshfield S, et al. “Just because it's out there, people aren't going to use it.” HIV self-testing among young, Black MSM, and transgender women. AIDS Patient Care STDs. 2015;29:617-624.

44. Lippman SA, Moran L, Sevelius J, et al. Acceptability and feasibility of HIV self-testing among transgender women in San Francisco: a mixed methods pilot study. AIDS Behav. 2016;20:928-938. 
45. Singer M, Clair S. Syndemics and public health: reconceptualizing disease in bio-social context. Med Anthropol Q 2003;17:423-441.

46. Stall R, Mills TC, Williamson J, et al. Association of co-occurring psychosocial health problems and increased vulnerability to HIV/AIDS among urban men who have sex with men. Am J Public Health 2003;93:939-942. 


\section{Figure legend}

Figure 1: Predicted probability of HIV related stigma and Perceived Transgender stigma on HIV testing with $95 \% \mathrm{CI}$

Figure 2: Predicted probability of Perceived Transgender stigma on HIV status with 95\% CI Figure 3: Predicted probability of Enacted Transgender stigma on HIV status with 95\% CI 
Table 1 Participant characteristics among a sample of transgender women in Jamaica $(n=137)$

\begin{tabular}{|c|c|c|}
\hline Variables & Mean (SD) & $\begin{array}{l}\text { Frequency } \\
(\%)^{*}\end{array}$ \\
\hline Age $(n=130)$ & $\begin{array}{l}24.25 \text { (4.54) median=24 (range 15- } \\
44)\end{array}$ & 130 \\
\hline Monthly income in US Dollar ( $\mathrm{n}=114$ ) & $\begin{array}{l}225.45(337.88) \text { median }=123.45 \\
\text { (range } 0-2469)\end{array}$ & 114 \\
\hline \multirow[t]{5}{*}{ City of residence } & Kingston & $92(67.15)$ \\
\hline & Montego Bay & $3(2.19)$ \\
\hline & Ochos Rios & $27(19.71)$ \\
\hline & Spanish Town & $10(7.30)$ \\
\hline & Others & $5(3.65)$ \\
\hline \multirow[t]{4}{*}{ Education (n=135) } & Less than high school & $26(19.26)$ \\
\hline & Completed high school & $67(49.63)$ \\
\hline & Attended some college & $20(14.81)$ \\
\hline & Completed college or higher & $22(16.30)$ \\
\hline \multirow[t]{5}{*}{ Employment $(\mathrm{n}=130)$} & $\begin{array}{l}\text { Employed or self-employed full } \\
\text { time }\end{array}$ & $37(37.98)$ \\
\hline & $\begin{array}{l}\text { Employed or self-employed part } \\
\text { time }\end{array}$ & $36(17.05)$ \\
\hline & Not employed: student & $14(10.85)$ \\
\hline & Not employed: on assistance & $9(6.98)$ \\
\hline & No source of income & $35(27.13)$ \\
\hline \multirow[t]{3}{*}{ Place of residence $(\mathrm{n}=134)$} & In my own house or apartment & $30(22.06)$ \\
\hline & $\begin{array}{l}\text { In other people's house or } \\
\text { Apartment }\end{array}$ & $89(65.44)$ \\
\hline & Outside & $14(10.29)$ \\
\hline \multirow[t]{4}{*}{ Relationship status ( $\mathrm{n}=136$ ) } & Married & $4(2.94)$ \\
\hline & Living together & $23(16.91)$ \\
\hline & Dating-not living together & $37(27.21)$ \\
\hline & Casual dating & $14(10.29)$ \\
\hline
\end{tabular}


No current partner

$31(22.79)$

Multiple partners/ polyamorous

How often have you been in jail for being Ever

Yes

$71(51.82)$

Any sex work involvement

Sexual orientation

Number of lifetime sexual partners $(n=136)$

Ever experienced forced sex

Ever experienced physical violence

$(n=136)$

Substance use (alcohol \&drugs) in the

past 3 months

How often do you get drunk/high when having sex $(n=68)$
Sex work exchange for a place to

$27(19.85)$

stay, food or transportation

Sex work exchange for money

$64(47.06)$

Sex work exchange for drugs or

$6(4.41)$

alcohol

Heterosexual (straight)

$40(31.01)$

Bisexual

15 (11.63)

Lesbian/Gay

61 (47.29)

Queer

13 (10.08)

19.47 (26.43) median=10 range $(1-136$

150)

Yes

63 (46.32)

Yes

62 (45.93)

Yes

67 (49.26)

Never

$11(16.42)$

Sometimes

$23(34.33)$

Often

22 (32.84)

Always

11 (16.42)

99 (92.52)

107

42(30.66)

137

Yes

103 (75.74)

Yes

30 (21.90)

Yes 
Lifetime STI history $(\mathrm{n}=83)$

Yes

$11(13.25)$

HIV status $(n=103)$

Positive

26 (25.24)

Self-report

Positive

11(10.68)

Serological/lab tested in this study Positive

15(14.56)

*Percentages calculated from non-missing responses for each variable. 
Table 2. Univariate and multivariate logistic modeling of factors associate with HIV testing and HIV status among a sample of transgender women in Jamaica

\begin{tabular}{|c|c|c|c|c|c|c|c|c|}
\hline \multirow[t]{2}{*}{ Variables } & \multicolumn{4}{|c|}{ HIV testing } & \multicolumn{4}{|l|}{ HIV status } \\
\hline & $\begin{array}{l}\text { Unadjusted } \\
\text { logistic regression } \\
\text { analyses, OR } \\
(95 \% \mathrm{CI})\end{array}$ & $\begin{array}{l}\mathrm{p} \\
\text { Value }\end{array}$ & $\begin{array}{l}\text { Adjusted logistic } \\
\text { regression } \\
\text { analyses, }{ }^{*} \text { OR } \\
(95 \% \mathrm{CI})\end{array}$ & $\begin{array}{l}\mathrm{p} \\
\text { Value }\end{array}$ & $\begin{array}{l}\text { Unadjusted } \\
\text { logistic regression } \\
\text { analyses, OR } \\
(95 \% \mathrm{CI})\end{array}$ & $\begin{array}{l}\mathrm{p} \\
\text { Value }\end{array}$ & $\begin{array}{l}\text { Adjusted logistic } \\
\text { regression } \\
\text { analyses, }{ }^{*} \text { OR } \\
(95 \% \mathrm{CI})\end{array}$ & $\begin{array}{l}\mathrm{p} \\
\text { Value }\end{array}$ \\
\hline Age & $1.09(0.98-1.20)$ & 0.110 & & & $1.02(0.93-1.12)$ & 0.664 & & \\
\hline Monthly income & $0.99(0.99-1.00)$ & 0.640 & & & $0.99(0.99-1.00)$ & 0.084 & & \\
\hline \multicolumn{9}{|l|}{ City } \\
\hline Kingston (ref) & 1 & & & & 1 & & & \\
\hline Ocho Rios & $\begin{array}{l}13.43(1.74- \\
103.70)\end{array}$ & 0.013 & $\begin{array}{l}11.60(1.48- \\
91.06)\end{array}$ & 0.020 & $0.33(0.07-5.26)$ & 0.154 & $0.27(0.05-1.48)$ & 0.132 \\
\hline Spanish Town & 1 (omitted) & & & & $2.74(0.43-17.64)$ & 0.289 & $0.56(0.10-3.27)$ & 0.520 \\
\hline \multicolumn{9}{|l|}{ Relationship status } \\
\hline Married/living together (ref) & 1 & & 1 & & 1 & & & \\
\hline Dating-not living together & $0.93(0.23-3.66)$ & 0.915 & $0.29(0.04-2.26)$ & 0.238 & $0.3(0.07-1.33)$ & 0.113 & $0.06(0.01-0.43)$ & 0.005 \\
\hline Casual dating & $1.04(0.17-6.54)$ & 0.964 & $0.61(0.04-10.31)$ & 0.729 & $1.4(0.32-6.10)$ & 0.654 & $0.32(0.05-2.05)$ & 0.228 \\
\hline No current partner & $0.60(0.15-2.31)$ & 0.455 & $0.16(0.02-1.22)$ & 0.077 & $1.43(0.43-4.72)$ & 0.556 & $0.36(0.07-1.78)$ & 0.208 \\
\hline $\begin{array}{l}\text { Multiple } \\
\text { partners/polyamorous }\end{array}$ & $0.13(0.03-0.48)$ & 0.002 & $0.04(0.01-0.31)$ & 0.002 & $0.64(0.16-2.58)$ & 0.527 & $0.19(0.03-1.12)$ & 0.066 \\
\hline \multicolumn{9}{|l|}{ Intrapersonal factors } \\
\hline Perceived HIV risk & $2.28(1.41-3.68)$ & 0.001 & $2.42(1.36-4.28)$ & 0.003 & $1.82(1.17-2.85)$ & 0.008 & $1.67(1.02-2.72)$ & 0.041 \\
\hline
\end{tabular}




\begin{tabular}{|c|c|c|c|c|c|c|c|c|}
\hline Drug use in past 3 months & $0.76(0.62-0.94)$ & 0.012 & $0.74(0.58-0.95)$ & 0.018 & $0.94(0.75-1.17)$ & 0.568 & $0.98(0.78-1.24)$ & 0.421 \\
\hline Depression & $1.24(0.99-1.55)$ & 0.058 & $1.34(1.01-1.77)$ & 0.041 & $1.33(1.02-1.73)$ & 0.032 & $1.39(1.06-1.82)$ & 0.018 \\
\hline Self-rated health & $1.04(0.64-1.69)$ & 0.861 & $1.11(0.63-1.95)$ & 0.717 & $0.48(0.28-0.81)$ & 0.007 & $0.55(0.30-0.98)$ & 0.044 \\
\hline Lifetime STI history & omitted & & & & $\begin{array}{l}28.85(5.74- \\
145.09)\end{array}$ & 0.000 & $\begin{array}{l}56.79(5.12- \\
630.33)\end{array}$ & 0.001 \\
\hline Sex work involvement & $1.10(0.51-2.39)$ & 0.806 & $1.22(0.49-3.02)$ & 0.671 & $1.63(0.68-3.90)$ & 0.273 & $1.67(0.61-4.51)$ & 0.316 \\
\hline \multicolumn{9}{|l|}{ Social/Interpersonal factors } \\
\hline Number of sexual partners & $1.01(0.99-1.04)$ & 0.190 & $1.01(0.99-1.03)$ & 0.408 & $1.01(0.99-1.03)$ & 0.065 & $1.02(1.00-1.04)$ & 0.041 \\
\hline Get drunk/high when having sex & $0.44(0.24-0.82)$ & 0.009 & $0.49(0.25-0.95)$ & 0.036 & $0.93(0.52-1.69)$ & 0.817 & $1.10(0.58-2.10)$ & 0.763 \\
\hline Need for social support & $1.01(0.96-1.06)$ & 0.762 & $1.02(0.96-1.08)$ & 0.613 & $1.09(1.02-1.16)$ & 0.012 & $1.09(1.01-1.18)$ & 0.022 \\
\hline Quality of social support & $1.09(0.92-1.29)$ & 0.332 & $1.09(0.89-1.34)$ & 0.405 & $0.79(0.65-0.97)$ & 0.022 & $0.79(0.64-0.97)$ & 0.025 \\
\hline Ever experienced forced sex & $2.64(1.15-6.08)$ & 0.022 & $3.83(1.42-10.35)$ & 0.008 & $3.18(1.27-7.93)$ & 0.013 & $4.14(1.49-11.51)$ & 0.006 \\
\hline Ever experienced physical abuse & $2.50(1.08-5.74)$ & 0.032 & $4.11(1.44-11.72)$ & 0.008 & $2.73(1.12-6.66)$ & 0.028 & $3.75(1.39-10.12)$ & 0.009 \\
\hline \multicolumn{9}{|l|}{ Structural factors } \\
\hline Perceived transgender stigma & $1.23(1.08-1.39)$ & 0.001 & $1.23(1.06-1.42)$ & 0.005 & $1.19(1.03-1.38)$ & 0.017 & $1.26(1.06-1.51)$ & 0.009 \\
\hline Enacted transgender stigma & $1.02(0.94-1.10)$ & 0.604 & $1.07(0.97-1.19)$ & 0.184 & $1.07(1.00-1.18)$ & 0.050 & $1.16(1.04-1.29)$ & 0.008 \\
\hline HIV-related stigma & $0.96(0.93-0.99)$ & 0.003 & $0.96(0.92-0.99)$ & 0.012 & $0.99(0.97-1.01)$ & 0.335 & $0.99(0.97-1.03)$ & 0.977 \\
\hline Have a health care provider & $4.24(1.38-12.98)$ & 0.011 & $5.89(1.46-23.77)$ & 0.013 & $0.65(0.27-1.58)$ & 0.340 & $0.60(0.22-1.64)$ & 0.315 \\
\hline Have been to jail for being & $0.28(0.12-0.67)$ & 0.004 & $0.28(0.10-0.78)$ & 0.015 & $1.03(0.37-2.85)$ & 0.952 & $1.42(0.47-4.27)$ & 0.535 \\
\hline \multicolumn{9}{|l|}{ transgender } \\
\hline \multicolumn{9}{|l|}{ Housing status } \\
\hline Own house/apartment (ref) & 1 & & 1 & & 1 & & 1 & \\
\hline $\begin{array}{l}\text { Other people's house or } \\
\text { apartment }\end{array}$ & $1.45(0.56-3.80)$ & 0.444 & $2.16(0.75-6.23)$ & 0.153 & $1.30(0.40-4.27)$ & 0.666 & $1.37(0.40-4.63)$ & 0.613 \\
\hline
\end{tabular}


Live outside

$0.36(0.10-1.37)$

$0.134 \quad 0.57(0.14-2.34) \quad 0.433$

$4.87(1.10-21.69)$

0.038

$5.93(1.27-27.74)$

0.024 *Adjusted for age and monthly income. 